\title{
COMPARISON OF TWO WIDELY USED ATYPICAL ANTIPSYCHOTICS OLANZAPINE VERSUS RISPERIDONE IN TERMS OF METABOLIC OUTCOMES
}

\author{
Shiraz Hussain, Nomita Imtiaz*, Malik Awais Amin**, Sana Khan**, Siddique Kakar** \\ Combined Military Hospital Bahawalpur/National University of Medical Sciences (NUMS) Pakistan, *Armed Forces Institute of Mental \\ Health/National University of Medical Sciences (NUMS) Rawalpindi Pakistan, **Pakistan Naval Ship Shifa Hospital, Islamabad/National \\ University of Medical Sciences (NUMS) Pakistan
}

\begin{abstract}
Objective: To compare the metabolic outcomes in psychiatric patients treated with Olanzapine and Risperidone. Study Design: Quasi experimental study.

Place and Duration of Study: The study was conducted at Armed Forces Institute of Mental Health, Rawalpindi, from Aug 2016 to Jan 2017.

Methodology: In this study 114 newly diagnosed psychiatric patients taking atypical anti-psychotics were selected and placed randomly into two groups i.e. group A (Olanzapine) andgroup B (Risperidone), 57 patients each. Patients of either gender, 20 to 60 years' age, clinically diagnosed new cases having psychiatric illness using DSMV were selected consecutively. Baseline and six months' end study data were collected and compared.

Results: Total 14 out of 109 (5 patients lost follow up) patients developed metabolic syndrome. Among these 10 $(18.18 \%)$ were in group A while 4 (7.41\%) were in group B. Patients receiving Olanzapine were 2.58 times more prone to develop metabolic syndrome compared to the Risperidone receiving [RR= 2.58 \{C.I. 0.85009, 7.62703\}]. Weight gain $(p$-value $=0.0048)$, increased Waist circumference $(p$-value $=0.00867)$ and elevated Blood Pressure $(p$ value $=0.0563$ ) were seen more significantly with use of Olanzapine.

Conclusion: Olanzapine although associated with good efficacy but indeed with more serious and long-term side effects like impaired blood glucose tolerance, dyslipidemia and increase weight. Psychiatrist must screen and continuously monitor such patients.
\end{abstract}

Keywords: Atypical antipsychotics, Dyslipidemia, Hyperglycemia, Metabolic Syndrome (MetS).

This is an Open Access article distributed under the terms of the Creative Commons Attribution License (http://creativecommons.org/licenses/by/4.0), which permits unrestricted use, distribution, and reproduction in any medium, provided the original work is properly cited.

\section{INTRODUCTION}

There is rapid and proportional increase in the prevalence of psychiatric illness including schizophrenia and bipolar disorder throughout the world. To an estimate as much as Seven Hundred Million $(>1 \%)$ people are suffering from debilitating mental illness globally. It is stipulated that $10-16 \%$ of the Pakistani population is affected from mild to moderate psychiatric illness ${ }^{1,2}$. Patients affected from schizophrenia die 10-15 years earlier as compared to the general population. Although suicide is much frequently reported cause of death but its incidence is only $10 \% 3,4$. In fact; the cardiovascular, metabolic comorbidities (like diabetes mellitus) and other complications cause majority of deaths among psychiatric

Correspondence: Dr Shiraz Hussain, Department of Psychiatry, CMH Bahawalpur Pakistan

Received: 22 Oct 2019; revised received: 27 Nov 2019; accepted: 12 Dec 2019 diseases patients. These complications are due to lack of proper and timely treatment of these debilitating mental illnesses ${ }^{5,6}$.

Antipsychotic drugs are the foundation of treatment of many psychiatric disorders as well as prevention of impending complications. Despite of their benefits upto $30-40 \%$ patients do not respond to atypical antipsychotics. Almost $50 \%$ patients are reported to developserious side effects ${ }^{7}$. These drugs seem to be linked with a wide range of morbidities like metabolic syndrome such as weight gain, impaired glucose metabolism, dyslipidemia. Moreover; associated with early mortality due to conditions like cardiovascular diseases and diabetes mellitus ${ }^{8}$.

Antipsychotic drugs vary considerably from one another in their effective dose, way of administration, pharmacokinetics, side effects and cost, all these factors effect choice of an 
antipsychotic drug for a particular patient. Monitoring of patients for metabolic adverse effects is mandatory while prescribing second-generation antipsychotics to reduce their cardio-metabolic hazards ${ }^{9,10}$. However; the psychiatrists frequently use atypical antipsychotics in patients with schizophrenia and other psychiatrist illnesses without keen care of safety and hazard. Studies have shown dyslipidemia and hyperglycemia are common side effects of these medications but most of the psychiatrists are usually unaware and not routinely monitor such side effects7,8,10. Risperidone and olanzapine are widely used second generation atypical antipsychotics. Studies done in western populations proposed a more worsened metabolic side effects profile with these agents ${ }^{11,12}$.

There was no any aggressive research conducted to compare the safety, efficacy and metabolic adverse effects of these second-generation antipsychotics in Pakistani population. The current study was based on rationale of non-availability of relevant data. The current study was exe-cuted with the objective to compare the metabolic outcomes of two commonly used atypical antipsychotics (Olanzapine or Risperidone) in Pakistani psychiatric patients. This study provides evidence of generating the recommendations for choosing the better antipsychotic medicine along with need of monitoring, prevention or treatment on earlier basis.

\section{METHODOLOGY}

This quasi experimental trial was carried out over a period of six months from March to August 2018, at outpatient department of Armed Forces Institute of Mental Health, Rawalpindi. Sample size calculated was 114 based on expected prevalence of dyslipidemia taken as $50 \% 13$ with margin of error $8 \%$ \& confidence level of $95 \%$. Sample was collected through consecutive sampling technique. After taking permission from hospital ethical review committee patients of either gender, 20 to 60 years of age, clinically diagnosed new cases having psychiatric illness like Schizophrenia, Bipolar disorder and Mental
\& Behavioral disorder due to Substance Abuse using Diagnostic and Statistical Manual of Mental Disorders V were selected. The written consent was taken from an immediate family member (parent, spouse, sibling, daughter or son) who was living with the patient for at least 6 months and involved directly in giving care to the patient.

Two groups were made viz group A (Olanzapine) while group B (Risperidone) and the patients were assigned to a group randomly using opaque envelope technique.

Olanzapine. According to the Product Information, the starting dose should be $5-10 \mathrm{mg} /$ day, and may be adjusted up to $20 \mathrm{mg} /$ day after clinical reassessment. Clinical experience suggests mean doses are about $13 \mathrm{mg} /$ day. Hence, for the purposes of this study, the clinically relevant dose of olanzapine was considered to be $10-15$ $\mathrm{mg} /$ day $^{13}$.

Risperidone. The Product Information states that the dose range should be 4-6 mg/day. This is in line with clinical practice, and the results of dose-ranging studies. Thus 4-6 mg/day was considered to be the clinically relevant dose ${ }^{13}$. Patients receiving anticonvulsants, antidepressants, lithium, or any antipsychotics medicine for last 3 months were excluded. Patients withsignificant physical diseases like Diabetes Mellitus, dyslipidemia, Hypothyroidism or Hyperthyroidism, HIV/AIDS, Tuberculosis, Liver Cirrhosis, Chronic Kidney Disease or Cushing syndrome and pregnant females were also not included.

Parameters likebody weight, height and blood pressure were measured by a trained researcher. Clinical data, demographic dataand family history of diabetes mellitus of patients was also recorded during the study period. Data was collected on Urdu version of prescribed proforma. Patients were kept nil per oral after 0000 hrs, and on the same daytheir plasma lipid and glucose levels were monitored by standard laboratory methods. Two milliliters were collected in the standard bottle and was sent for the blood sugar, while remaining three milliliters of blood 
sample was sent for the measurement of fasting Lipid profile, including total cholesterol (TC), TGs, HDL and LDL from standardized laboratory.

It was followed by treatment within each group with respective antipsychotic drug. Dosage administered as per the recommended plan. Follow up was carried out three-month interval and end study data was collected at end of six months. Clinical and demographic variables were compared both pretreatment and post treatment forecasting metabolic syndrome.

Descriptive and stratified analysis [mean \& standard deviation (Mean \pm SD) on continuous variables while proportions and percentages of categorical variables] was performed with application of chi-square taking the $p$-value $<0.05$ as significant using SPSS version-21.

\section{RESULTS}

There were 57 patients in each treatment group (viz; group-A = Olanzapine \& group-B= Risperidone) at the time of start of study however; at the end (months follow up) there were two patients lost to follow up in group-A while three in group B. Results are generated accordingly and are listed in table-I \& II respectively. Patients in both the groups were almost identical regarding basic demographic data at time of registration. Figure showed the comparison of both groups in terms of basic demographic variables. Following the National Cholesterol Education Program Adult Treatment Panel III definition of metabolic syndrome, it was found that at the six months follow up after treating patients with one of either atypical antipsychotic - there were 14 patients who developed metabolic syndrome. Among these 10 (18.18\%) were in group A while in group B affected were 4 (7.41\%). Other patients who fulfilled one or more but not all criteria of metabolic syndrome were found in both groups but overall group A (Olanzapine) had higher number of these compared to group B (risperidone). Weight gain ( $p$-value $=0.0048)$, increased waist circumference $(p$-value $=0.00867)$ and elevated blood pressure $(p$-value $=0.0563)$ were
Table-I: Pre-treatment statistics of all patients $(n=114)$.

\begin{tabular}{|c|c|c|c|c|}
\hline Variable & Group & Min & Max & Mean \pm SD \\
\hline \multirow{2}{*}{ Age (years) } & $\mathrm{A}$ & 29 & 59 & $49.4 \pm 11.71$ \\
\hline & $\mathrm{B}$ & 31 & 60 & $48.9 \pm 12.34$ \\
\hline \multirow{2}{*}{ Weight } & $\mathrm{A}$ & 52 & 98 & $73.54 \pm 10.13$ \\
\hline & B & 59 & 95 & $70.23 \pm 7.85$ \\
\hline \multirow{2}{*}{ Height } & $\mathrm{A}$ & 4.90 & 6.03 & $5.52 \pm 0.26$ \\
\hline & B & 4.89 & 5.95 & $5.44 \pm 0.23$ \\
\hline \multirow{2}{*}{ BMI } & $\mathrm{A}$ & 17.88 & 39.91 & $25.95 \pm 4.32$ \\
\hline & B & 18.10 & 38.55 & $24.85 \pm 4.24$ \\
\hline \multirow{2}{*}{$\begin{array}{l}\text { Mean Blood } \\
\text { Pressure }\end{array}$} & $\mathrm{A}$ & 95 & 126 & $108.2 \pm 11.4$ \\
\hline & $\mathrm{B}$ & 90 & 125 & $110.5 \pm 12.9$ \\
\hline \multirow{2}{*}{$\begin{array}{l}\text { Duration of } \\
\text { disease }(\mathrm{m})\end{array}$} & $\mathrm{A}$ & 2 & 8 & $4.14 \pm 1.91$ \\
\hline & B & 2 & 7 & $4.12 \pm 1.82$ \\
\hline \multirow{2}{*}{$\begin{array}{l}\text { Glucose } \\
(\mathrm{mg} / \mathrm{dL})\end{array}$} & $\mathrm{A}$ & 81 & 111 & $94.2 \pm 10.6$ \\
\hline & B & 80 & 112 & $97.9 \pm 10.8$ \\
\hline \multirow{2}{*}{$\begin{array}{l}\text { Total } \\
\text { cholesterol, } \\
\mathrm{mg} / \mathrm{dL}\end{array}$} & A & 167 & 266 & $228.15 \pm 50.65$ \\
\hline & B & 162 & 260 & $235.49 \pm 48.33$ \\
\hline \multirow{2}{*}{$\begin{array}{l}\text { HDL } \\
\text { cholesterol, } \\
\text { mg/dL }\end{array}$} & $\mathrm{A}$ & 32.20 & 52.20 & $45.20 \pm 12.06$ \\
\hline & B & 31.04 & 51.04 & $44.04 \pm 13.73$ \\
\hline \multirow{2}{*}{ Age (years) } & $\mathrm{A}$ & 89.45 & 252.43 & $172.71 \pm 54.03$ \\
\hline & B & 87.28 & 261.29 & $170.02 \pm 51.37$ \\
\hline \multirow{2}{*}{ Weight } & $\mathrm{A}$ & 71.2 & 95.9 & $85.8 \pm 9.8$ \\
\hline & B & 74.2 & 92.2 & $86.5 \pm 9.1$ \\
\hline
\end{tabular}

GroupA (Olanzapine) $=57$; Group B (Risperidone) $=57$.

Table-II: Post-treatment statistics of all patients at the six months follow up $(n=109)$.

\begin{tabular}{|c|c|c|c|c|}
\hline Variable & Group & Min & Max & Mean \pm SD \\
\hline \multirow{2}{*}{ Weight } & A & 54 & 112 & $83.33 \pm 12.44$ \\
\hline & $\mathrm{B}$ & 56 & 109 & $74.12 \pm 7.91$ \\
\hline \multirow{2}{*}{ BMI } & A & 18.78 & 39.19 & $26.51 \pm 4.61$ \\
\hline & B & 19.02 & 37.22 & $25.15 \pm 4.55$ \\
\hline \multirow{2}{*}{$\begin{array}{l}\text { Mean Blood } \\
\text { Pressure }\end{array}$} & A & 90 & 145 & $120.5 \pm 19.14$ \\
\hline & $\mathrm{B}$ & 95 & 155 & $118.5 \pm 21.29$ \\
\hline \multirow{2}{*}{$\begin{array}{l}\text { Glucose } \\
(\mathrm{mg} / \mathrm{dL})\end{array}$} & A & 102 & 130 & $114.7 \pm 14.06$ \\
\hline & $\mathrm{B}$ & 101 & 126 & $112.9 \pm 13.2$ \\
\hline \multirow{2}{*}{$\begin{array}{l}\text { Total } \\
\text { cholesterol, } \\
\mathrm{mg} / \mathrm{dL}\end{array}$} & A & 201 & 298 & $242.85 \pm 45.5$ \\
\hline & $\mathrm{B}$ & 191 & 287 & $240.12 \pm 45.22$ \\
\hline \multirow{2}{*}{$\begin{array}{l}\text { HDL Choles- } \\
\text { terol, mg/dL }\end{array}$} & A & 29.30 & 52.20 & $41.50 \pm 10.5$ \\
\hline & $\mathrm{B}$ & 30.10 & 51.04 & $42.10 \pm 11.64$ \\
\hline \multirow{2}{*}{$\begin{array}{l}\text { Triglycerides, } \\
\text { mg/dL }\end{array}$} & A & 99.51 & 271.12 & $192.50 \pm 61.43$ \\
\hline & $\mathrm{B}$ & 95.78 & 271.44 & $197.44 \pm 62.17$ \\
\hline \multirow{2}{*}{$\begin{array}{l}\text { Waist circum- } \\
\text { ference }(\mathrm{cms})\end{array}$} & A & 78.5 & 102.2 & $90.5 \pm 9.9$ \\
\hline & B & 80.4 & 101.1 & $89.2 \pm 9.6$ \\
\hline
\end{tabular}

Group A (Olanzapine) $=55 ;$ Group B (Risperidone) $=54$.

2 patients (group A) and 3 patients (group B )lost to follow up. 
seen more significantly with use of Olanzapine (table-III). Patients receiving Olanzapine were

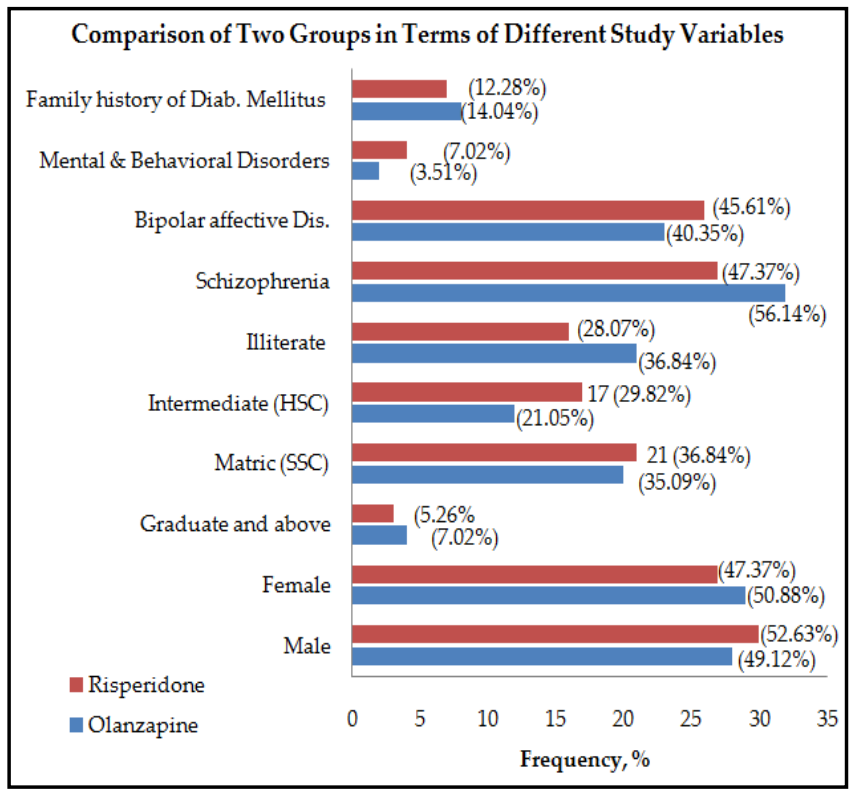

Figure: Basic demographic comparison of patients of both groups.

2.58 times more prone to develop metabolic syndrome compared to the Risperidone receiving [relative risk $=2.58$ \{C.I. 0.85009, 7.62703\}].

Table-III: Comparison of post-treatment metabolic syndrome $(\mathrm{n}=109)$.

\begin{tabular}{|c|c|c|c|}
\hline \multirow{2}{*}{$\begin{array}{l}\text { Outcome } \\
\text { variable }\end{array}$} & \multicolumn{2}{|c|}{ Group } & \multirow{2}{*}{$\begin{array}{c}\text { Chi- } \\
\text { square } \\
p \text {-value }\end{array}$} \\
\hline & $\begin{array}{c}A \\
n=55(\%)\end{array}$ & $\begin{array}{c}B \\
n=54(\%)\end{array}$ & \\
\hline $\begin{array}{l}\text { Metabolic } \\
\text { syndrome }\end{array}$ & $10(18.18)$ & $4(7.41)$ & $\begin{array}{l}2.8256 \\
0.0927 \\
\end{array}$ \\
\hline Impaired FBS & $18(32.73)$ & $11(20.37)$ & $\begin{array}{l}2.1307 \\
0.1443\end{array}$ \\
\hline Dyslipidemia & $17(30.91)$ & $7(12.96)$ & $\begin{array}{c}3.1876 \\
0.023\end{array}$ \\
\hline Weight gain & $17(30.91)$ & $5(9.26)$ & $\begin{array}{l}7.9278 \\
0.0048 \\
\end{array}$ \\
\hline $\begin{array}{l}\text { Increased Waist } \\
\text { circumference }\end{array}$ & $16(29.09)$ & $5(9.26)$ & $\begin{array}{c}6.8897 \\
0.00867 \\
\end{array}$ \\
\hline $\begin{array}{l}\text { Elevated Blood } \\
\text { Pressure }\end{array}$ & $11(20)$ & $4(7.41)$ & $\begin{array}{l}3.6408 \\
0.0563\end{array}$ \\
\hline
\end{tabular}

\section{DISCUSSION}

The high proportion of Pakistani patients with schizophrenia and other psychiatric conditions are either untreated or improperly treated.
The metabolic syndrome may be a cause or consequence of these problems which increases the requirement of monitoring of this issue ${ }^{14,15}$. A study by Alosaimi et alli found that as much as $41.2 \%$ psychiatric patients were having with metabolic syndrome. While, another recent study by Alswat (2017) ${ }^{17}$ reported that occurrence of metabolic syndrome was 39\% amongst hospitalized psychiatric patients. There are different causes of metabolic syndrome- one important of these is use of atypical antipsychotic drugs (SGA). Although these medicines provide good results however; side effects like weight gain, impaired glucose tolerance and dyslipidemia with the consequent risks of diabetic ketoacidosis and cardiovascular disease raise critical concerns and warrant wise selection of these agents ${ }^{18}$.

In Asia and particularly Pakistan the day to day psychiatry practice, Olanzapine is most commonly used medicine followed by others. While comparing it with the Risperidone, the current study noted that olanzapine was associated with more than twice incidence of metabolic syndrome. [relative risk=2.58 \{C.I. 0.85009, 7.62703\}]. Both risperidone and olanzapine were generally well-tolerated and efficacious in the treatment of patients. Results of other studies like Alméras and coworkers ${ }^{19}$ which assessed patients taking olanzapine and risperidone for 6 months are in concordance with the current study and found that risk of MetS is thrice with use of olanzapine compared to Risperidone. They found higher FBS levels, raised triglycerides, increased levels of apolipoprotein B, decreased HDL levels with use of olanzapine compared to risperidone.

Another finding of this study was increased mean weight and waist circumference of patients which is in accordance with previous studies like Sacchetti and coworkers reported more than 5\% of weight gain than baseline with olanzapine, while $17 \%$ of patients managed with risperidone $^{20}$. Another study by Ye W, et al, from Japan found that more than two thirds of patients needed to switch from risperidone to olanzapine and they improved in symptoms however; there was statistically significant weight gain in all of 
them ${ }^{21}$. In contrast to previous studies $12,16,17,19$ the present study indicated larger difference between olanzapine $(18.18 \%)$ and risperidone $(7.41 \%)$ in terms of metabolic syndrome which however was statistically not significant ( $p$-value $=0.0927)$. The monitoring must includetotal cholesterol, triglycerides, and weight in patients of schizo-phrenia taking olanzapine ${ }^{22}$.

Kumar et al reports that less severity of negative symptoms among olanzapine users than the risperidone while other factors like increased weight, increased lipid and glucose levels were comparable in both groups ${ }^{22}$. We also noted that HDL levels were lower with use of risperidone, compared with olanzapine. However, trigly-ceride, total cholesterol and LDL levels were lower in risperidone group.

We have not analyzed the effect of mean dose of antipsychotics as risk factors as we used a standard dose (olanzapine dose: 10 to $20 \mathrm{mg}$ daily and risperidone dose: 4 to $8 \mathrm{mg}$ daily). Previous studies $^{12,14-17,19}$ found association of mean dose of anti psychotics with metabolic adverse effects may be due to interaction of environmental and genetic factors ${ }^{23}$.

With these preliminary results it was concludedthat there were certain limitations in this study. It was a single centered study without long term follow-up. The data collectors were not blinded of the groups and treatment therefore researcher bias may have affected the study. Further; these results do not represent the entire population. Yet, the study with all its limitations has highlighted very important aspect of treatment of psychiatric patients and related side effects. We recommend that in future prospective studies with larger double and triple blinding should be conducted in order to better understand the safety and efficacy of different treatment regimen.

\section{CONCLUSION}

The current preliminary results of a prospective study have highlighted a very significant aspect of health care of psychiatrically ill patients in Pakistan. Olanzapine although associated with good efficacy in negative and extrapyramidal symptoms of schizophrenia and other mental disorders is indeed associated with more serious and long-term side effects like impaired blood glucose tolerance, dyslipidemia and increase weight. The psychiatrist needs to screen patients before prescribing these antipsychotics as well as monitoring the patients continuously so as to prevent long term adverse consequences.

\section{CONFLICT OF INTEREST}

This study has no conflict of interest to be declared by any author.

\section{REFRENCES}

1. World Health Organization. WHO Pakistan celebrates World Mental Health Day. URL: http://www.emro.who.int/pak/ pakistan-news/who-pakistan-celebrates-world-mental-healthday.html

2. WHO World Mental Health Surveys International College Student Project: Prevalence and distribution of mental disorders. J Abnormal Psychol 2018; 127(7): 623-38.

3. Habib O, Rizwan HC, Waheed MA, Malik SB, Minhas IA, Faiz M. A profile of patients attending a psychiatric outpatient clinic. J Pak Psychiatr Soc 2018; 15(1): 17-22.

4. Harvey SB, Deady M, Wang MW, Mykletun A, Butterworth P, Christensen $\mathrm{H}$, et al. Is the prevalence of mental illness increasing in Australia? Evidence from national health surveys and administrative data, 2001-2014. Med J Aust 2017; 206(11): 490-93.

5. Storch JA, Speyer H, Norgaard HCB, Hjorthoj C, Krogh J, Mors $\mathrm{O}$, et al. Associations between clinical and psychosocial factors and metabolic and cardiovascular riskfactors in overweight patients with schizophrenia spectrum disorders - Baseline and two-years findings from the CHANGE trial. Schizophr Res 2018; 199(2018): 96-102.

6. Liu NH, Daumit GL, Dua T, Aquila R, Charlson F, Cuijpers P, et al. Excess mortality in persons with severe mental disorders: a multilevel intervention framework and priorities for clinical practice, policy and research agendas. World Psychiatry 2017; 16(1): 30-40.

7. Zhang Y, Liu Y, Su Y, You Y, Ma Y, Yang G, et al. The metabolic side effects of 12 antipsychotic drugs for the treatment of schizophrenia on glucose: A network meta-analysis. BMC Psych 2017; 17(1): 373-75.

8. Correll CU, Ng-Mak DS, Stafkey-Mailey D, Farrelly E, Rajagopalan K, Loebel A. Cardiometabolic comorbidities, readmission, and costs in schizophrenia and bipolar disorder: A real-world analysis. Ann Gen Psychiatr 2017; 16(1): 9-11.

9. Fawzy N, Shabrawy A, Youssef A. Prevalence and risk factors of metabolic syndrome among drug-naive psychotic patients. Egypt J Psychiat 2015; 36(2): 101-05.

10. Haupt DW, Rosenblatt LC, Kim E, Baker RA, Whitehead R. Prevalence and predictors of lipid and glucose monitoring in commercially insured patients treated with second generation antipsychotic agents. Am J Psychiatr 2009; 166(3): 345-53.

11. Kumar SPN, Anish PK, Rajmohan V. Olanzapine has better efficacy compared to risperidone for treatment of negative symptoms in schizophrenia. Indian J Psychiatry 2016; 58(3): 311-16.

12. Shafti S, Gilanipoor M. A comparative study between olanzapine and risperidone in the management of schizophrenia. Schizophr Res Treatment 2014; 2014: 307202. 
13. Mudge MA, Davey PJ, Coleman DK, Montgomery W, Croker VS, Mullen K, et al. A comparison of olanzapine versus risperidone for the treatment of schizophrenia: a meta-analysis of randomised clinical trials. Int J Psychiatry Clin Pract 2005; 9(1): 3-15.

14. Ferns G. Cause, consequence or coincidence: The relationship between psychiatric disease and metabolic syndrome. Trans Metab Syndrome Res 2018; 2018(1): 23-38.

15. Vancampfort D, Correll CU, Galling B, Probst M, De Hert M, Ward PB, et al. Diabetes mellitus in people with schizophrenia, bipolar disorder and major depressive disorder: a systematic review and large scale meta-analysis. World J Psychiatr 2016; 15(2): 166-74.

16. Alosaimi FD, Abalhassan M, Alhaddad B, Alzain N, Fallata E, Alhabbad A, et al. Prevalence of metabolic syndrome and its components among patients with various psychiatric diagnoses and treatments: A cross-sectional study. Gen Hosp Psychiatr2017; 45(1): 62-69.

17. Alswat KA, Alnemari AK, Alghamdi I, Almalki AA, Al-Thomali B, Mahfouz T. Prevalence of metabolic syndrome in the hospitalized psychiatric patients. Med Arch 2017; 71(6): 412-16.
18. Gonçalves P, Araújo J, Martel F. Antipsychotics-induced metabolic alterations: focus on adipose tissue and molecular mechanisms. Eur Neuropsycho Pharmacol 2015; 1(1): 1-16.

19. Jeon SW, Yong-Ku Kim. Unresolved issues for utilization of atypical antipsychotics in schizophrenia: Antipsychotic Polypharmacy and Metabolic Syndrome. Int J Mol Sci 2017; 18(10): 2174.

20. Shafti SS, Kaviani H. Quetiapine versus aripiprazole in the management of schizophrenia. Ther Adv Psychopharmacol 2015; 5(3): 166-71.

21. Ye W, Fujikoshi S, Nakahara N, Takahashi M, Ascher-Svanum $\mathrm{H}$, Ohmori $\mathrm{T}$. Improved outcomes following a switch to olanzapine treatment from risperidone treatment in a 1-year naturalistic study of schizophrenia patients in Japan. Psychiatry Clin Neurosci 2012; 66(1): 313-21.

22. Kumar PNS, Anish PK, Rajmohan V. Olanzepine has better efficacy compared to risperidone for treatment of negative symptoms in schizophrenia. Ind J Psych 2016; 58(3): 311-16.

23. Dilla T, Moller J, O'Donohoe P, Alvarez M, Sacristan JA, Happich $\mathrm{M}$, et al. Long-acting olanzapine versus long-acting risperidone for schizophrenia in Spain - a cost-effectiveness comparison. BMC Psychiat 2014; 14(2): 298. 